\title{
PROCESSO SUCESSÓRIO: ESTUDO DE CASO EM UMA ORGANIZAÇÃO FAMILIAR DE PEQUENO PORTE DO RAMO IMOBILIÁRIO CONDUZIDA POR MULHERES
}

\section{SUCCESSION PROCESS: A REAL ESTATE FAMILY BUSINESS LED BY WOMEN CASE STUDY}

\section{Andreia Pandolfi dos Santos}

Mestra em Administração pela Universidade do Sul de Santa Catarina (Unisul). E-mail: andripandolfi@yahoo.com.br (Brasil)

\section{Chaiene Oliveira}

Graduanda do Curso de Direito na Universidade do Sul de Santa Catarina (Unisul). E-mail: chai_oliveira@hotmail.com (Brasil)

\section{Simone Sehnem}

Doutora em Administração pela Univali. Professora do Mestrado Profissional e Doutorado Acadêmico em Administração da UNOESC. Professora do Mestrado em Administração da Unisul. E-mail: simonesehnem_adm@yahoo.com.br (Brasil)

\section{Jorge Brognoli}

Mestrando do Programa de Pós-graduação em Administração da Universidade do Sul de Santa Catarina (Unisul). E-mail: jorge.brognoli@ unisul.br (Brasil)

Data de recebimento do artigo: 29-01-2017

Data de aceite do artigo: 05-12-2017 Doi: http://dx.doi.org/10.7769/gesec.v8i3.638 


\title{
PROCESSO SUCESSÓRIO: ESTUDO DE CASO EM UMA ORGANIZAÇÃO FAMILIAR DE PEQUENO PORTE DO RAMO IMOBILIÁRIO CONDUZIDA POR MULHERES
}

\section{RESUMO}

As empresas familiares brasileiras possuem notoriedade na economia, representando um total de aproximadamente $90 \%$ dentre as empresas do país, conforme dados do Instituto Brasileiro de Geografia e Estatísticas [IBGE], (2014). Logo, um grande número de organizações desse perfil, no mundo todo, vivencia ou estará passando pelo processo de sucessão, seja profissional ou familiar. Este estudo tem como objetivo analisar o processo sucessório de uma empresa familiar no ramo imobiliário, conduzida por mulheres, unindo os temas sucessão familiar e gênero, cuja abordagem é realizada em uma única pesquisa, via estudo de caso único, fazendo uso da análise de conteúdo das narrativas dos entrevistados para a construção qualitativa do conhecimento. $\mathrm{O}$ estudo evidenciou que o processo sucessório aconteceu de forma indutiva, que as estratégias adotadas para o processo da sucessão indiretamente também foram indutivas. Como contribuição da pesquisa, foi elaborada uma proposta de um modelo de planejamento de sucessão familiar, que atende a necessidade de capacitação profissional desses administradores e se sobrepõe aos interesses pessoais.

Palavras-chave: Processo sucessório. Empresa familiar. Gênero.

\section{SUCCESSION PROCESS: A REAL ESTATE FAMILY BUSINESS LED BY WOMEN CASE STUDY}

\begin{abstract}
The Brazilian family businesses have high importance in the economy, representing near $90 \%$ of all Brazilian companies, according to the Instituto Brasileiro de Geografia e Estatística [IBGE], (2014). In this scenario, a large number of family business is going through family business succession process. This study aims to analyze the succession process of a real estate family business led by women, comprising both themes: succession and gender. The approach consists in a singular case study based on qualitative analysis of the narrative content collected in interviews. This study shows that the succession process and the strategies used were both inductive. A succession planning for family business is proposed, in order to attend the necessity of professional training for managers over lapping personal interests.
\end{abstract}

Keywords: Succession process. Family Business. Gender. 


\section{INTRODUÇÃO}

As empresas familiares constituem uma forma de organização que tem sido considerada como predominante nos diferentes setores da economia e que contribui de forma significativa para o crescimento e desenvolvimento da sociedade. De acordo com Serviço de Apoio às Micros e Pequenas Empresas [Sebrae], (2014), nos últimos cinco anos, as empresas familiares foram as que mais cresceram e são as que têm mais possibilidade de se manter no mercado em comparação com outros empreendimentos. Conforme dados do IBGE (2014), as empresas familiares representam 90\% das empresas em atividades no Brasil.

O que define uma empresa familiar de acordo com Gersick, Davis, Hampton \& Lansberg (1997), Leach e Bogod (2006) é o fato de ela estar ligada a uma família e consequentemente ser controlada pelos familiares. Logo, necessariamente influenciada pela dinâmica dos membros das famílias, cuja tipicidade é reconhecida por uma diversidade de atores organizacionais. Este fato que torna as empresas familiares definitivamente uma classe diferenciada de organizações, nas quais se faz necessário que sejam influenciadas por valores ou interesses familiares.

Entre as empresas familiares podem-se identificar vários indicadores que irão dos mais simples, como as organizações cujo controle societário está nas mãos de uma familia, até indicadores mais complexos onde são incluídos alguns requisitos, entre eles, estar na segunda geração, como também os familiares ocuparem cargos de direção ou outras funções a nível estratégico (Oliveira \& Silva, 2012). Assim a sucessão em empresas familiares não é um evento raro, o que leva o processo de sucessão ocorrer em média a cada 20 a 25 anos (Schlepphorst \& Moog, 2014).

Dentro do universo das empresas familiares, o tema da sucessão vem sendo pesquisado via diferentes abordagens tornando-se um dos principais focos de estudo, haja vista que ainda existem muitas lacunas no que se refere a compreensão e interpretação do campo da sucessão familiar (Petry \& Nascimento, 2009). Ressalta-se que este tema continua sendo um desafio, e gera debates para a área organizacional (Blumentrittt, Mathews \& Marchisio, 2013).

A pesquisa realizada por Bird, Welsch, Astrachan e Pistrui (2002), por exemplo, mostra que a temática sucessão foi explicitada em $19 \%$ dos artigos mais citados no Journal FBR (Family Business Review). Já em outra pesquisa mais recente realizada por Debicki, Matterne, Kellermanns e Chrismann (2009) que analisou 291 artigos publicados entre os anos 
de 2001 e 2007, o estudo demonstrou que o tema de sucessão foi objeto de apenas $15 \%$ dos trabalhos publicados.

Estudo bibliométrico realizado por Santos, Oliveira \& Sehnem (2016), entre os anos de 2004 a 2015, nas seguintes bases de dados: Ebsco host Research Data bases (EBSCO), Scientific Eletronic Library Online (SCIELO), Scientific Periodicals Eletronic Library (SPELL), Science Direct e SCOPUS e nos eventos da Associação Nacional de Pós-graduação e Pesquisa em Administração (Anpad), por meio das análises das principais lacunas de pesquisas, identificou-se que além da temática sucessão ser pouco explorada no contexto empresarial familiar, a pesquisa revelou a carência, tanto na literatura nacional quanto na internacional, acerca da questão de gênero na sucessão familiar. Cruz Machado, Wetzel e Rodrigues (2008) reafirmam em sua pesquisa a existência de poucos estudos referentes à sucessão familiar e ressaltam o aumento do número de mulheres sucessoras, devido a crescente participação feminina em níveis gerenciais no mercado de trabalho.

Apesar de a participação das mulheres no mercado de trabalho ter aumentado nos últimos anos, ainda continua menor com relação à participação masculina. Ahrens, Landmann e Woywod (2015), por sua vez, mencionam que, no que se refere a gênero, a liderança feminina ainda está em um nível baixo em relação à inclusão no mercado de trabalho. Contribuem com a afirmação o Departamento Intersindical de Estatísticas e Estudos Socioeconômicos [Dieese], (2016), o qual relata, por meio de sua pesquisa, que em todas as regiões metropolitanas do Brasil a participação masculina no mercado de trabalho é maior.

Nesse contexto, a opção pelo tema de pesquisa justifica-se pelo interesse científico e social dos pesquisadores em compreender o universo que circunda a sucessão familiar em pequenas empresas dirigidas por mulheres. A pergunta que orienta esta investigação é: Como ocorreu o processo sucessório de uma pequena empresa familiar no ramo imobiliário passada de mãe para filha?

Diante desse cenário, o objetivo principal deste artigo é analisar o processo sucessório de uma empresa familiar no ramo imobiliário conduzido por mulheres.

Para que o objetivo geral seja alcançado, são propostos os seguintes objetivos específicos: a) descrever o histórico da organização e o estágio sucessório em que se encontra; b) verificar quais foram as estratégias adotadas para conduzir o processo sucessório e a preparação dos herdeiros; c) avaliar o processo sucessório a partir da perspectiva de legitimação do sucessor e satisfação do sucedido; d) identificar alternativas para aperfeiçoamento do processo sucessório operacionalizado na organização pesquisada. 
A intenção de desenvolver este estudo na área de empresas familiares busca, sobretudo, refletir criticamente sobre questões que podem agregar conhecimento no campo da administração e, assim, contribuir com um debate que ainda desafia a compreensão da comunidade acadêmica. Almejamos contribuir para o enriquecimento da literatura brasileira sobre questões de gênero na sucessão da empresa familiar, tema esse, pouco explorado em nível mundial e que vem sendo apontado por diversos teóricos como uma linha de pesquisa que precisa ser mais aprofundada, na medida em que casos de sucessão feminina se tornam mais decorrentes.

\section{SUCESSÃO FAMILIAR, CONCEITOS E CARACTERÍSTICAS}

A sucessão familiar é um processo contínuo de transferência multigeracional no qual se dá a transferência dos valores e da cultura da organização (Lambrecht, 2005). Também é complexa e muitas vezes é um processo moroso, que envolve "ações, eventos e desenvolvimentos que afetam a transferência do controle gerencial" entre os membros da familia (Massis, Chua \& Chrisman, 2008, p. 184). Já para Salvato e Corbetta (2013), a sucessão é abrangida como a transferência da liderança, dos papéis e do poder do precursor para seu sucessor.

Ferreira (2015) trata o processo sucessório como uma realidade do cotidiano organizacional, reconhecido como um fator de representativa importância na estratégia devido à influência que exerce no modelo de gestão, nos indicadores financeiros e nas relações sociopolíticas. A profissionalização da sucessão pode ser percebida como um processo de evolução em direção a um processo mais formalizado, em outros termos, pode também ser traduzida no desenvolvimento da estrutura organizacional (Pecanha \& Oliveira, 2015).

Dentre as ferramentas apresentadas pela literatura para a realização do processo sucessório está o planejamento da sucessão. Essa ferramenta é apontada como sendo a principal solução, a fim de evitar situações conflituosas, despreparo e futuras negligência que venham a prejudicar os negócios da familia (Sharma, Chrisman, Pablo \& Chua, 2001; Leone 2004; Grzybovski, Hoffmann \& Muhl 2008; Borges; Lima \& Carvalho, 2008). Ademais a comunicação no planejamento da sucessão é outro fator que contribui para que a relação existente entre o fundador, sucessores e envolvidos seja efetiva (Michael-Tsabari \& Weiss, 2015).

O processo de sucessão apresenta aspectos dificultadores e aspectos facilitadores. Porém, mesmo depois de alguns anos, cabe destacar o estudo realizado por Scheffer (1995). A 
autora define fatores que podem, de certa forma, dificultar o processo sucessório, dentre eles: lacunas na capacitação do sucessor, que se referem a desvios no autodesenvolvimento do herdeiro, tanto em sua educação formal quanto em aspectos gerenciais. E nos aspectos facilitadores Scheffer (1995), destaca o envolvimento da família no processo sucessório e à preparação do sucedido para o processo de sucessão. Oliveira, Albuquerque e Pereira (2013), corroboram enfatizando o facilitador da influência desempenhada pelas relações entre pais e filhos na construção da legitimidade.

Oliveira, Albuquerque e Pereira (2013) e Salvato e Corbetta (2013), destacam em suas pesquisas alguns fatores facilitadores do processo sucessório, que são: a comunicação, o plano de aposentadoria e a sucessão profissionalizada em empresas familiares, mostrando que deve existir envolvimento da família no processo sucessório, discussão e comunicação dos planos a todos os seus membros, ativos ou inativos.

Michael-Tsabari e Weiss (2015) relatam o impacto da má comunicação interpessoal durante a transição do processo de sucessão em um estudo de caso e os resultados mostraram que a comunicação deficiente ocasionou divergências e confrontos entre o fundador, o sucessor e os demais envolvidos, por conseguinte, isso reduziu a harmonia familiar durante o processo de sucessão. Michael-Tsabari e Weiss (2015) denominam essas situações de "armadilhas da comunicação".

\subsection{Questão de gênero na sucessão familiar}

Alguns estudos indicam que uma maior atenção vem sendo dispensada às questões de gênero e à participação das mulheres em empresas familiares (Dumas, 1998; Fitzgerald, Winter, Muller e Paul, 2001; Cappuyns, 2007; Lerner\& Malach-Pines, 2011). Embora a literatura destaque que as taxas de sucessão feminina são baixas, estudos, como a revisão de literatura de Gupta e Levenburg (2013), sugerem que as mulheres nas empresas familiares desempenham cada vez mais um papel ativo. Apesar da crescente introdução das mulheres em todas as esferas produtivas, e em especial, nos negócios de família (Cruz Machado, Wetzel \& Rodrigues, 2008; Jimenez, 2009), ainda existem diversas barreiras que as impedem de avançar (Machado, Silveira, Hoeltgebaum \& Gouvea, 2008), sendo a questão do gênero um fator importante na escolha do sucessor (Ahrenset al., 2015).

Alguns fatores culturais contribuem, muitas vezes, para que a atuação feminina na sucessão dos negócios familiares ocorra por meio da influência silenciosa, tal como mães sendo mediadoras no processo sucessório (Janjuha-Jivraj \& Woods, 2002). Haberman e 
Danes (2007) confirmam ao enfatizarem que a derrocada dos mitos e preconceitos sobre a aceitação de gestoras mulheres nas empresas familiares representa um desafio vagaroso, uma vez que as desigualdades de gênero estão intensamente enraizadas na cultura familiar e em seu processo de socialização. Por outro lado, Lerner e Malach-Pines (2011) ressaltam a existência de outra corrente em torno do debate sobre o papel da mulher nas empresas familiares, enfatizando que as organizações familiares oferecem oportunidades às mulheres que outros negócios geralmente não possibilitam.

Em pesquisa realizada por Vera \& Dean, (2005), foram verificados os desafios das filhas sucessoras em empresas familiares. As autoras constataram que os principais desafios enfrentados foram a rivalidade dos funcionários e a dificuldade no equilibrio entre a vida profissional e a vida pessoal, que no decorrer do processo acabaram encontrando problemas com seus pais após a sucessão.

Jimenez (2009) assinala que as diferenças na socialização entre filhos e filhas no âmbito da empresa familiar são claramente visíveis e relata que as filhas geralmente passam menos tempo na empresa e desenvolvem um menor número de habilidades gerenciais, ao mesmo tempo em que não são encorajadas a seguir carreira junto ao negócio da família.

Cruz Machado et al. (2008), realizaram uma pesquisa com sete herdeiras de empresas familiares de setores distintos, na cidade do Rio de Janeiro. As autoras buscaram analisar as percepções das herdeiras sobre as principais questões relativas ao estágio inicial da sucessão, em especial, sobre a preparação para o ingresso na organização. As constatações dessa pesquisa indicaram que não houve um planejamento formal de sucessão das herdeiras com antecedência suficiente que lhes garantissem uma clareza em relação às suas responsabilidades, aos caminhos que precisavam percorrer até a sucessão ou à sua identidade profissional na empresa familiar. Mesmo nos casos em que a herdeira é âncora - ou seja, pertence à familia com apenas descendentes mulheres ou com poucos homens e sobre quem a responsabilidade de liderar a empresa esteve presente desde a infância -, a entrada não foi discutida com antecedência. A pesquisa ainda aponta, claramente, pontos de discriminação de gênero, com delimitações distintas de tempo e espaço femininos e masculinos. Alguns horários de trabalho, alguns locais e algumas atividades não são permitidos às filhas sob o pretexto da proteção (Cruz Machado et al., 2008).

Schröder, Schmitt-Rodermund e Arnaud(2011), ao analisar uma amostra de 106 empresas familiares, também identificaram da mesma forma a preferência paterna para que homens assumam o comando das suas empresas familiares. Por outro lado, Allen e Langowitz (2003) salientam que as mulheres sucessoras em empresas familiares são mais produtivas em 
comparação aos homens, de acordo com seu levantamento de dados no ano de 2002 com 873 empresas de propriedade de família nos EUA.

Ahrenset et al. (2015) concretizaram um estudo que abrangeu 804 sucessores em empresas familiares alemãs, entre o período de 2002 e 2008, para verificar como a questão de gênero para o processo sucessório é percebida. Nas observações, evidenciaram que os empresários de organizações familiares parecem ter preferência por sucessores do gênero masculino quando se trata de assumir os negócios da familia. Os autores analisaram, também, que se ambos os gêneros estão presentes entre os filhos dos fundadores que representam possíveis sucessores, o sucessor da família do gênero masculino é escolhido em média 81,2\% a mais em relação ao feminino.

\section{MÉTODO}

O estudo se desenvolveu em uma empresa familiar privada, dirigida por mulheres, localizada no município de Florianópolis, estado de Santa Catarina, nos meses de junho e julho de 2016. A justificativa para escolha da organização se deu por meio do objetivo da pesquisa, uma vez, que há predominância de acordo com a literatura em sucessões passadas de pai para filho. No entanto, realizou-se uma busca junto à junta comercial do município e verificou-se que dentro do porte e perfil traçado havia poucas empresas, das quais a única que se propôs a participar do estudo foi a organização investigada.

A empresa familiar atua há 29 anos no setor imobiliário e no município, e é considerada de pequeno porte, de acordo com o critério de classificação adotados pelo Serviço Brasileiro de Apoio às Micro e Pequenas Empresas (Sebrae) (n.d.), IBGE, (n.d.) e o Banco Nacional de Desenvolvimento Econômico e Social (BNDES), (n.d.), considerando o número de funcionários, e o faturamento anual no ramo do setor.

Para a elaboração desta pesquisa, realizou-se uma investigação de abordagem qualitativa, com o objetivo metodológico descritivo, de natureza básica com método indutivo. Dessa forma, a estratégia de pesquisa escolhida foi o estudo de caso único. De acordo com Yin \& Pinnelli (2005), o estudo de caso único, oferece ao pesquisador a possibilidade de se aprofundar na compreensão do fenômeno pesquisado, além de consentir a produção de análises mais detalhada, considerando as evidências presentes e ampliando possibilidade de explorar interpretações alternativas.

O trabalho envolve pesquisa de campo, bibliográfica, análise documental e web gráfica. Para coleta de dados em campo, foram realizadas entrevistas nos dias 24,28 e 30 de 
junho no ano de 2016, com roteiro semiestruturado, registradas por meio de gravação emáudio e transcritas na íntegra, e os documentos foram analisados por meio da técnica de análise de conteúdo e de narrativas, conforme preceitos expostos por Bardin (1977). Além das entrevistas, para a caracterização da instituição, foram coletados dados do site da empresa pesquisada e efetuada visita in loco.

A observação, realizada por meio de visita à organização, fez parte do processo de coleta de informações e foi fundamental para compreender a complexidade das ações desenvolvidas. Kets de Vries e Carlocke Florent-Treacy (2009), ao destacarem o pressuposto sistêmico do observador como parte do sistema, recomendam que pesquisadores que trabalham com familias empresárias não ignorem as suas emoções. Ao contrário, indicam que as identifiquem, absorvam e as usufruam como importantes fontes de dados.

Foi utilizada também a triangulação, que significa olhar para o mesmo fenômeno, ou questão de pesquisa, a partir de mais de uma fonte de dados. Informações advindas de diferentes ângulos podem ser usadas para corroborar, elaborar ou iluminar o problema de pesquisa. A amostragem baseou-se na decisão dos pesquisadores, configurando-se em uma amostragem não probabilística por intencionalidade. Desta pesquisa participaram das entrevistas a sucessora herdeira, a fundadora em exercício, e a gestora administrativa (testemunha-chave) a seguir:

- Sucessora herdeira - entrevistada "A", assumiu a sucessão desde maio de 2014, estando há dois anos e dois meses no comando da organização. Tem 23 anos, possui formação no exterior; graduada em Relações Internacionais, pela universidade de Oregon e é solteira. Além da graduação no exterior, realizou o curso técnico em Transações Imobiliárias, credenciado pelo Conselho Regional de Corretores de Imóveis (Creci) (n.d.), e está cursando Tecnólogo de Gestão em Recursos Humanos.

- Fundadora - entrevistada 'B”, é bacharel em Direito, especializada em Direito Empresarial, possui graduação em Estudos Sociais, 54 anos de idade. Trabalha na organização há 23 anos e, em maio do ano de 2016, passou a ocupar a posição de conselheira e mentora.

- Gerente Administrativo- entrevistada "C", graduada em Administração, casada, 32 anos, trabalha na organização há mais de seis anos.

A técnica de análise de dados deste estudo segue algumas etapas proposta por Bardin (2004): pré-análise; exploração do material ou codificação; tratamento dos resultados e interpretação. O primeiro passo incide em organizar e preparar os dados para analisar - são dados extraídos das entrevistas -, considerado como uma fase de tratamento do material. Segunda etapa: exploração do material, iniciar uma análise detalhada com objetivo de 
codificação dos dados e identificação das unidades de registro. Essa fase é considerada importante para esse estudo, pois visa permitir uma descrição exata das características pertinentes ao conteúdo expresso no texto. Terceiro momento é caracterizado pelo tratamento dos resultados, considerado como uma análise reflexiva e crítica. Em sequência, o último passo é a apresentação dos dados, em que é realizada a interpretação e extração do significado dos dados obtidos nas etapas anteriores.

A análise dos dados deu-se a partir das entrevistas e visa facilitar a compreensão da interpretação. Os pontos de conteúdo mais significativos foram por vezes narrados por meio de trechos dos discursos das herdeiras. Suas falas foram fielmente reproduzidas e eventuais erros gramaticais foram mantidos para preservar a naturalidade dos relatos. Ressalta-se que questões éticas como: os nomes das entrevistadas bem como da organização pesquisada foram preservados. Logo, as entrevistadas serão tratadas no decorrer do texto como entrevistadas A, B e C e a empresa por XXX.

\section{APRESENTAÇÃO E ANÁLISE DOS DADOS}

\subsection{Histórico da organização e o estágio sucess ório em que se encontra}

A empresa estudada é a XXX Imóveis, uma imobiliária que trabalha com venda, locação e administração de imóvel, fundada em 1987, por dois sócios. No princípio, o fundador começou informalmente com plaquinhas e uma bicicleta na entrada da praia de Canasvieiras, alugando imóveis especificamente para os turistas. A empresa, com o passar do tempo, foi formalmente constituída na rua Felipe Schmidt, no centro de Florianópolis, em uma sala alugada e foi evoluindo no decorrer de sua trajetória. Após dez anos de sua constituição, as esposas dos fundadores foram convidadas para trabalhar na área administrativa da imobiliária, pois se constatou a necessidade de organizar de forma geral a empresa e de um toque feminino. De acordo com a entrevistada B [...] as mulheres gostam das coisas mais certinhas [...] o sistema na época era falho, os computadores eram muito antigos, e os programas operacionais também [...]. Já consolidada no mercado, a empresa muda-se para um local próprio no centro da cidade, oferecendo mais conforto e comodidade para seus clientes.

Em 1997, surge uma nova etapa, os sócios decidem seguir caminhos diferentes e a imobiliária, passa a ser conduzida e administrada por um dos fundadores e por sua esposa. A esposa do fundador a partir de então, começa a assumir a gerência dos negócios e, mesmo o 
marido conduzindo a gestão da empresa, ela se propôs a trabalhar e aprender em cada setor. Além de sócios, souberam separar muito bem casamento e negócios. Essa união resultou em dois filhos para o casal: uma menina -a primogênita - e um menino. Alguns anos depois, o sócio majoritário veio a falecer, e sua esposa, que já participava da gestão dos negócios resolveu gerir a imobiliária sozinha, junto com sua equipe. Nessa mesma trajetória, os filhos decidem ir estudar nos EUA. Os negócios foram ampliados, novas empresas adquiridas e vendidas.

Durante 23 anos a entrevistada trabalhou na imobiliária à frente dos negócios, e com a volta da filha para o Brasil, já formada, e com muitas ideias novas, a antecessora, decide conversar com seus dois filhos sobre os negócios da família. Manifestou-se no sentido de que se não fosse desejo de os filhos darem continuidade à empresa familiar, ela estava disposta a vender a organização. Não cogitava a ideia de uma sucessão profissional, pois temia que alguém que não fosse membro da família, não manteria os mesmos valores e a cultura da empresa, os quais foram construídos com base na figura de seu fundador. Neste momento, a filha manifestou seu interesse de assumir a sucessão dos negócios da familia. O filho não manifestou interesse em assumir a sucessão, e deu apoio total à irmã.

O ano de 2015 marcou uma nova fase, agora com a filha sucessora à frente dos negócios. Fato que vai ao encontro com os dizeres de Schlepphorst \& Moog, (2014) de que o rodízio de sucessores em organizações familiares acontece em média a cada 20 e 25 anos, pois, há sempre um percentual de dirigentes que se afastam nesse período de tempo de trabalho - assim, a sucessão em empresas familiares não é um evento raro.

Há 29 anos no mercado, a imobiliária XXX, composta por 16 funcionários diretos, encontra-se na segunda geração. Além do quadro funcional a empresa possui três sócios: antecessora, agora conselheira, e os dois herdeiros. A filha mais velha foi quem assumiu a direção da organização e o filho mais novo trabalha na parte comercial de vendas e locação de imóveis.

Partindo da perspectiva de que a sucessão é um processo construído pelo sucedido, pelo sucessor e pelos demais membros da organização e da familia, pode-se afirmar que o processo sucessório da imobiliária começou a se desenhar no ano de 2011 com a ida da mãe para os EUA ao encontro dos filhos. De acordo com a entrevistada (B) [...] ou vocês tocam, ou eu vou vender a empresa, porque eu não quero mais [...] Não havendo interesse por parte do filho mais novo e com a filha já formada, esta despertou-se em estar assumindo os negócios da família, conforme relatou a entrevistada (A): 
[...] Sempre fomos muito democráticos lá em casa né, e até assim bem democráticos, todo mundo sempre teve voz pra $[s i c]$ decidir o que fazia. Foi o rumo que as coisas tomaram, meu irmão não se manifestou, não teve vontade e eu decidi vir trabalhar todos os dias e tomar frente, sou muito espaçosa e a transição foi meio que eu tomando conta de tudo. Foi até mais rápido do que a gente imaginava justamente porque eu sou metida (entrevistada A).

Observou-se claramente que acordos societários sempre existiram na XXX Imóveis, pois conforme exposição da antecessora, mesmo o filho não despertando o interesse de comandar, ele sempre esteve presente no contrato social, o qual é dividido em partes iguais entre os três: mãe, filha e filho. Conforme Passos, Bernhoeft \& Teixeira, (2006) salientam que o primeiro passo que a familia deve dar é realizar o diagnóstico societário. Após o diagnóstico societário, os familiares devem discutir o acordo societário para que os direitos e os deveres sejam regulados, e para que haja maior compromisso por parte dos membros da empresa (Passoset al., 2006).

Para a escolha do sucessor, observou-se que não houve preferência de gênero, mas logo uma decisão lógica seguiu a idade, formação superior completo, e acima de tudo o respeito pelo desejo e sonhos individuais de cada filho. Dahl \& Moretti (2008) afirmam que esse viés de gênero é devido à forte preferência dos homens para filhos, enquanto apenas as mulheres parecem ter uma ligeira preferência por filhas sobre filhos.

Verificou-se que o processo sucessório da organização estudada não foi de fato planejado, no entanto foi mais intuitivo. Segundo antecessora entrevistada (B) [...] talvez em outra situação, momento, tivesse pensando e feito diferente, esperado um pouco mais [...].

[...] Não foi planejada a sucessão. A ideia era que eu ficasse aqui um tempo, aprendesse como as coisas funcionam e aí tomasse frente. E aí eu não sei nem te dizer quando que foi bem o momento, foi vamos decidir, então fizemos uma reunião e eu falei: ô pessoal, a partir de agora eu tomo frente das coisas, (entrevistada A).

Dados da Family Business Network (FBN) (2016), revelam que 63\% das empresas familiares brasileiras não desenvolveram nenhum tipo de planejamento sucessório. Borges, Lima e Carvalho (2008), abordam a importância de se planejar a sucessão, e defendem a ideia de compreendê-la como um processo e não como um momento organizacional. Isso significa que a sucessão não deve ser entendida como algo estático, mas sim como um processo contínuo que se desenvolve desde a infância do futuro sucessor, por meio da socialização e 
prossegue, durante a adolescência até o estado adulto, quando o herdeiro assume definitivamente o cargo do fundador (Borges et al., 2008).

\subsection{Estratégias adotadas para conduzir o processo sucessório e a preparação dos herdeiros}

Dentre as estratégias desenvolvidas para o preparo do processo sucessório está a preparação dos herdeiros por meio das seguintes ações: organização setorial antes da entrada dos filhos na empresa; a convivência dos filhos com os pais no ambiente da empresa durante os períodos de férias; o incentivo aos estudos, para que os herdeiros tivessem ensino superior completo antes de adentrar em qualquer organização; o apoio para que os herdeiros tivessem experiência de estudo fora do Brasil, e consequentemente desenvolvesse contato com outras culturas e uma segunda língua.

[...] A minha filha morava nos EUA, e durante as férias ela vinha comigo pra [sic] empresa, já estava despertando o interesse dela nessa coisa. Ficou seis meses trabalhando comigo, voltou para os EUA [...] Aí ela começou a frequentar a empresa todos os dias. (Entrevistada B).

Após a antecessora mencionar seu interesse de se desligar da instituição e o despertar da filha em assumir o negócio da família, houve uma preparação da sucessora por cerca de seis meses. Segundo relato da entrevistada C, [...] a mãe tentou passar tudo para filha, desde contrato, como lidar com clientes, fornecedores, funcionários, deu uma aula para ela, passando de tudo um pouco até a herdeira ter noção de tudo [...]. No entanto, antes de a filha voltar para aprender a gerir a empresa, a mãe indutivamente, sem saber se a filha aceitaria o convite, contratou uma empresa de consultoria para organizar os departamentos/setores da imobiliária, pois gostaria de deixar tudo em ordem antes mesmo de afilha começar a trabalhar lá. Porém, na época a proprietária não cogitou a ideia de contratar uma assessoria externa para auxiliar no processo sucessório:

[...] Eu não pensei nessas consultorias de maneira diferente, pela vivência no ramo eu achei que conseguiria passar para minha filha, claro já auxiliada por essas consultorias anteriores, nunca pensei em outro tipo de processo sucessório que não fosse esse de mãe pra[sic] filha, eu ensinando pra ela as coisas que a gente tinha. Como a educação foi minha, questão de princípios, consideração com o ser humano, e eu acho que esse é o mais importante, e ela tem esses valores. Meu jeito de 
comandar é muito matriarcal. Quando tenho que ser mãe eu sou mãe, mas quando tem que ser amiga eu sou amiga, então a gente consegue trabalhar esse lado, é dela também. (Entrevistada B).

Segundo Dugan, Krone, LeCouvie, Pendergast, Kenyon-Rouvineze Schuman (2011) ao criar seus filhos, as mulheres transmitem valores que serão essenciais para que a próxima geração mantenha o equilibrio e a continuidade dos negócios. Valores como o trabalho árduo, o cuidado com as pessoas que as cercam e a compreensão de que a familia deve servir ao negócio, ou seja, as mães ensinam seus filhos a amar a empresa (Duganet al., 2008).

Uma das estratégias buscada com o processo sucessório em trâmite, foi a necessidade de a herdeira se aperfeiçoar na parte técnica da organização e procurar conhecimento para liderar pessoas. Para suprir tal necessidade, iniciou curso técnico de corretor de imóveis pelo Conselho Regional de Corretores de Imóveis de Santa Catarina (Crecisc), (n.d.), e uma nova graduação no curso de Gestão de Pessoas, para poder compreender tecnicamente como procede uma corretora de imóveis bem como trabalhar, conviver e gerir pessoas. Outra estratégia apontada pela filha durante o processo de sucessão foi o fato de a mãe ter desenvolvido o papel de mentora e conselheira, visto pela entrevistada A, como um facilitador do processo sucessório. De acordo com Michael-Tsabarie Weiss (2015), a relação direta existente entre o antecessor e o sucessor é outro aspecto fundamental para a sucessão, pois o auxilio nesta relação é defendido com a utilização de observadores e conselheiros.

Analisou-se que muitas estratégias realizadas para o processo sucessório foram indutivas pela parte da precursora, uma vez que a sucessão não foi planejada antecipadamente, e que não houve desde o início o desejo, a manifestação de incentivar aos filhos para a continuidade dos negócios. De acordo com a entrevistada B, sempre foram respeitados os sonhos e desejos de cada filho. Se a filha não manifestasse interesse em dar continuidade na empresa da familia, certamente a empresa teria sido vendida, pois o que importa é a felicidade dos filhos. Tal evidência vai ao encontro dos dizeres de Cruz Machado et al. (2008), que destacam que uma explicação para essa situação, seria a de que, talvez fugindo do papel autoritário, a proprietária da empresa não forçaria o ingresso dos filhos no negócio. Possivelmente, para deixá-los mais livres em todo o processo de sucessão, evitaria também formalizar um plano de entrada, conversar sobre o assunto, planejar cargos, metas e etapas (Cruz Machado et al., 2008). 


\subsection{Análise do processo sucessório a partir da perspectiva de legitimação do sucessor e satisfação do sucedido}

Após o período de preparação da sucessora, foi realizado voluntariamente o anúncio para os colaboradores, em seguida para os demais parceiros, clientes e fornecedores, sobre a passagem do "bastão" para conduzir os negócios da família. Como sempre, foram separadas as cotas acionárias da empresa, sendo apenas necessária a legitimação da sucessão através da posse da filha. De acordo com as entrevistadas, logo após a legitimação da sucessão, a antecessora afastou-se da organização e foi viajar por um período de três meses, ficando completamente desligada da empresa. Observou-se que o objetivo da antecessora era o de que a filha desenvolvesse seu modo próprio de gerir, pois cada pessoa tem suas atribuições e maneiras de liderar e a precursora não gostaria de influenciar nas decisões que a herdeira dali para frente viesse a tomar, de acordo com o relato:

[...] Eu deixei um manual pronto de todas as partes da empresa, expliquei qual era filosofia da gente, isso durou mais ou menos um ano esse processo e disse pra ela que então tava $[s i c]$ indo viajar. Foi um momento profissional que eu dei espaço pra [sic] ela, mas a corda foi puxada por ela mesma, que sentiu que em algumas coisas não estava madura e pronta para fazer sozinha (Entrevistada B).

[...] Ela ficou um tempo afastada, ela ficou três meses em Miami. Nesse tempo que ela ficou afastada eu me virei e consegui sobreviver, mas não é a mesma coisa. Até brinco que ela achou que ia se aposentar, mas eu não vou deixar, porque preciso dela pra muita coisa, principalmente pra administrativo, financeiro, jurídico, que eu descobri que eu não tenho nem um pouco de interesse em tomar frente dessas coisas. (Entrevistada A).

Verificou-se que a sucessora de fato não estava preparada para assumir os negócios sozinha, pois demonstrou insegurança e o desejo de ter a mãe por perto. Nesse sentido, a literatura confirma que a entrada na empresa de forma repentina, sem um planejamento antecipado, gera no sucessor uma dificuldade de entender seu papel no negócio e de criar uma identidade clara naquele ambiente (Dumas, 1998; Vera\& Dean, 2005). No entanto, percebe-se a satisfação e o orgulho da mãe pela filha, pois segundo relato, a sucessora tem espírito inovador empreendedor, e conseguiu revolucionar muitas coisas boas na empresa, como melhorar o debate e cobrar excelência no atendimento aos clientes. 
Principais focos conflitos e rejeição no processo sucessório

Dentre os principais focos de conflitos e rejeições no processo sucessório da imobiliária XXX observados, destacam-se como maiores dificultadores: a falta de preparação do processo sucessório, a idade da sucessora, e a precipitação da herdeira ao assumir a empresa. No Quadro 1 são apresentados os principais focos de conflitos, rejeição e dificultadores na organização estudada combinados com os achados da literatura.

Quadro1: Principais focos de conflitos e rejeição no processo sucessório.

\begin{tabular}{|c|c|c|}
\hline Temas e problemas & Achados na literatura & $\begin{array}{l}\text { Os resultados mensurados das } \\
\text { entrevistas }\end{array}$ \\
\hline $\begin{array}{l}\text { 1. Rejeição por parte } \\
\text { dos colaboradores. }\end{array}$ & $\begin{array}{l}\text { Falta de confiança no potencial } \\
\text { sucessor, falta de compromisso com o } \\
\text { sucessor potencial, incapacidade de } \\
\text { sustentar os desafios da sucessão } \\
\text { (Massiset al., 2008). } \\
\text { Scheffer (1995) apresenta o } \\
\text { posicionamento dos funcionários mais } \\
\text { antigos, como uns dos fatores de } \\
\text { resistência para a sucessão, pois parte } \\
\text { desses colaboradores que se fazem } \\
\text { parte da organização por muitos anos, } \\
\text { demonstram inflexibilidade para acatar } \\
\text { o novo sucessor nas empresas } \\
\text { familiares. }\end{array}$ & $\begin{array}{l}\text {-Alta rotatividade dos funcionários (C); } \\
\text {-falta de preparo da sucessora em } \\
\text { conhecer todas as funções e setores, } \\
\text { chegando a controvérsias (C); } \\
\text {-fator idade, muito jovem pesou } \\
\text { bastante (C); } \\
\text {-muitas divergências de ideias } \\
\text { comparadas com a gestão anterior, } \\
\text { muitas mudanças impostas (C); } \\
\text { - dos funcionários mais antigos, que } \\
\text { hoje só são dois, o resto é tudo novo, } \\
\text { eles não conseguiam servir as duas ao } \\
\text { mesmo tempo, não sabiam a quem se } \\
\text { dirigir (B); } \\
\text {-teve bastante resistência por parte dos } \\
\text { funcionários, foi o que mais pegou } \\
\text { nessa situação (B); } \\
\text {-dos funcionários houve uma } \\
\text { resistência enorme; "porque ela é muito } \\
\text { jovem, ela é filha da dona, ela não sabe } \\
\text { de nada, quem sabe é a gente tem que } \\
\text { ser do nosso jeito"(B); } \\
\text { - as pessoas têm dificuldade de mudar, } \\
\text { acho que tiveram conflitos, muita } \\
\text { resistência (A). }\end{array}$ \\
\hline $\begin{array}{l}\text { 2.Rejeição por parte } \\
\text { dos clientes }\end{array}$ & $\begin{array}{l}\text { Dumas (1998) identificou em sua } \\
\text { pesquisa com } 702 \text { mulheres no Canadá }\end{array}$ & $\begin{array}{l}\text { - Fator idade, muito impactante saber } \\
\text { que uma menina de } 23 \text { anos iria }\end{array}$ \\
\hline
\end{tabular}




\begin{tabular}{|c|c|c|}
\hline & $\begin{array}{l}\text { que, ao assumir o comando do negócio, } \\
\text { a maioria delas encontrou problemas } \\
\text { variados, desde a dificuldade para } \\
\text { entender seu papel no negócio e serem } \\
\text { aceitas por clientes e fornecedores. } \\
\text { De acordo com Bornholdt (2005), } \\
\text { percebe-se que a posse por uma } \\
\text { posição na direção da organização } \\
\text { exige esforços, aceitação e a confiança } \\
\text { múltipla de todos os envolvidos no } \\
\text { processo, sejam eles herdeiros, } \\
\text { colaboradores, fornecedores e clientes. }\end{array}$ & $\begin{array}{l}\text { assumir os negócios daqui para frente } \\
\text { (C); } \\
\text {-teve algumas situações que clientes } \\
\text { passaram a ignorá-la em uma reunião } \\
\text { (B). }\end{array}$ \\
\hline $\begin{array}{l}\text { 3. Possíveis conflitos } \\
\text { e desentendimentos } \\
\text { entre mãe e filha. }\end{array}$ & $\begin{array}{l}\text { Conflitos/rivalidades/concorrência no } \\
\text { relacionamento pai-filho, relacionados } \\
\text { à alta sensibilidade de "consenso" do } \\
\text { negócio de família, falta de confiança } \\
\text { no potencial sucessor (Massiset al., } \\
\text { 2008). } \\
\text { Ainda de acordo com a literatura, } \\
\text { quando mãe e filha trabalham juntas, a } \\
\text { mãe seria muito controladora e a filha } \\
\text { seria muito crítica em relação à sua } \\
\text { mãe, há problemas de confiança } \\
\text { (Vera\& Dean, 2005). } \\
\text { mela tecnologia e pelas ciências } \\
\text { modernas. A juventude olha o futuro; o } \\
\text { empreendedor que se retira tem certa } \\
\text { tendência a "olhar o passado - sua } \\
\text { experiência". (Leone, 2004). } \\
\text { tendo a mesma idade, é compreensível } \\
\text { que seus estilos de gestão não sejam os } \\
\text { mesmos. A nova geração tem, em nível de vida muito mais } \\
\text { elevado e é, fortemente, influenciada }\end{array}$ & $\begin{array}{l}\text {-Muita gente mandando, a gente não } \\
\text { sabe quem obedecer, uma manda a } \\
\text { outra desmanda (C); } \\
\text { - falta de comunicação entre elas (C); } \\
\text { - às vezes esporadicamente uma está } \\
\text { chateada coma outra (C); } \\
\text { - falta de comunicação ainda vem a } \\
\text { pecar (B); } \\
\text {-o começo, que ela quis pegar tudo de } \\
\text { uma vez e eu me senti um pouco } \\
\text { descartada (B); } \\
\text { - minha filha é de outra geração e } \\
\text { trabalha muito participativa que pra } \\
\text { mim incomoda (B); } \\
\text { - aí eu fui morar sozinha e aí isso } \\
\text { melhorou um pouco e a gente foi } \\
\text { conhecendo melhor } \\
\text { relacionamento e separando a esfera } \\
\text { profissional e pessoal, porque tava } \\
\text { afetando nosso relacionamento pessoal } \\
\text { (A); } \\
\text {-“mãe tens que parar porque eu não tô } \\
\text { entendendo nada, não consigo } \\
\text { acompanhar” (A); } \\
\text { - teve uma época que foi difícil tá as } \\
\text { duas juntas (A); }\end{array}$ \\
\hline
\end{tabular}

Fonte: Os autores (2016). 
Em suma, observou-se que as dificuldades elencadas no Quadro 1 resultaram em rejeição, representada pela grande rotatividade dos colaboradores da empresa, e conflitos, inclusive entre a antecessora e a sucessora. Outro fator observado foi a total liberdade transferida em momento ainda não oportuno pela proprietária para a filha, o que gerou certos dilemas e controvérsias na relação familiar, os quais são apresentados na seção seguinte.

Dilemas e controvérsias entre família e negócios

Ao tratar sobre dilemas e controvérsias entre familia e negócios, observou-se que a familia possui um bom relacionamento e que negócios e familia, com a entrada da herdeira na organização, no início misturaram-se, gerando certo desconforto na relação das gerações. Contudo, esse fato logo foi sanado e separado, conforme relato das entrevistadas:

[...] morava junto com a minha mãe, então como a gente não definiu nenhuma regra, então não tinha horário, a gente tava [sic] vindo pra cá tava [sic] falando de negócio, a gente tava [sic] em casa tava [sic] falando de negócio, não tinha mais horário. Então, ficou bem difícil pra mim, mas aí eu fui morar sozinha e aí isso melhorou um pouco e a gente foi conhecendo melhor nosso relacionamento e separando a esfera profissional e pessoal, porque tava [sic] afetando nosso relacionamento pessoal essa coisa de ter que lidar e falar de negócios, em muitos momentos era muita informação [...] hoje eu me sinto muito mais confortável (Entrevistada A).

[...] O que vem acontecendo é que quando um tá se passando em conversar aos sábados sobre o cliente porque lembrou, o outro diz: "Hoje? Não.” A minha filha mora sozinha, não mora mais comigo, meu filho que mora comigo e também não tem o hábito de conversar sobre os negócios. (Entrevistada B).

Notou-se que dilema, família, propriedade, sempre foram muito bem separados na organização pesquisada. Porém, no início da sucessão o quesito gestão, negócios e família não estavam sendo separados, mas no decorrer do processo, tanto a antecessora e a herdeira, buscaram alternativas para sanar o problema. Essa análise vai ao encontro com a figura: modelo de três círculos da empresa familiar apresentada por Gersik, Davis, Hampton e Lansberg (1997), que é considerada uma ferramenta útil para a compreensão de possíveis conflitos interpessoais, dilema de papéis, prioridades e limites nos negócios familiares. 


\subsection{Alternativas para aperfeiçoamento do processo sucessório operacionalizado na organização pesquisada}

De acordo com o próprio relato das entrevistadas a sucessão deveria ter acontecido em momento futuro. Observou-se a necessidade de um amadurecimento profissional da herdeira. Verificou-se a falta de preparo, de conhecimento profissional alinhado com experiências profissionais no setor para lidar com situações do cotidiano.

Caso fosse possível refazer o processo sucessório, as entrevistadas elencaram que fariam as seguintes mudanças: planejamento do processo sucessório, preparação do candidato dentro da organização ou até mesmo em ambiente externos, mas no ramo imobiliário, o acompanhamento de todos os setores pelo herdeiro, ter o antecessor como guia para que possa acompanhá-lo, iniciar o processo sucessório com o candidato tendo experiências nas funções básicas da empresa. Como melhoria no processo sucessório também foi pontuado o perfil do candidato, a descoberta do que ele realmente deseja realizar e foco nesses objetivos. No momento em que está na organização, saber separar interesses pessoais fora do ambiente de trabalho.

Outro aspecto citado por uma das entrevistadas está relacionado aos valores culturais da organização. Segundo Lambrecht (2005), a sucessão familiar é um processo contínuo de transferência multigeracional no qual se dá a transferência dos valores e da cultura da organização. Esses valores devem ser preservados, e é por meio da convivência na organização que os filhos herdeiros os agregam, pois é o momento em que passam a entender a causa, podendo-se, então, cobrar e exigir.

Por outro lado, apurou-se que pelo fato de a sucessora ser jovem o bastante para assumir tamanha responsabilidade e pela sua qualidade de escolaridade, a herdeira possui espírito de liderança inovador e empreendedor, o que pode a longo prazo gerar mudanças positivas e construtivas, aprimorando os negócios da família com ideias novas e tecnologia, vindo a oferecer serviços diferenciados e inovadores que o mercado ainda não oferece, mercado este considerando tradicional no seu ramo.

Assim, a solução do processo sucessório passa, necessariamente, pela estruturação de um plano de sucessão que permita a continuidade dos negócios e, para alcançar tal objetivo, é necessário detectar quem está disposto a assumir as funções, mas também sendo considerada a preparação para a obtenção da competência necessária para a gestão e comando da empresa.

Com base neste estudo de caso e com a intenção de trazer uma contribuição para pequenas empresas familiares, propõem-se um planejamento sucessório em um fluxo. A 
Figura 1 ilustra elementos relevantes do processo sucessório, destacados para caso analisado e também pela literatura.

O aspecto temporal considerado para a conclusão de cada etapa do processo deve ser relativizado, uma vez que estará de acordo com as capacidades de cada pessoa. Levou-se em consideração a experiência dos entrevistados e da empresa estudada, estabelecendo-se um período entre o início e o fim para que o empreendedor possa perceber e preencher com aquilo que falta ao candidato à sucessão, sendo relativo à própria experiência pessoal, e por isso constitui-se como uma verdade individual da empresa que pode ser apropriada ou alterada em outras.

Figura 1: Planejamento e condução do processo sucessório para pequenas empresas familiares.

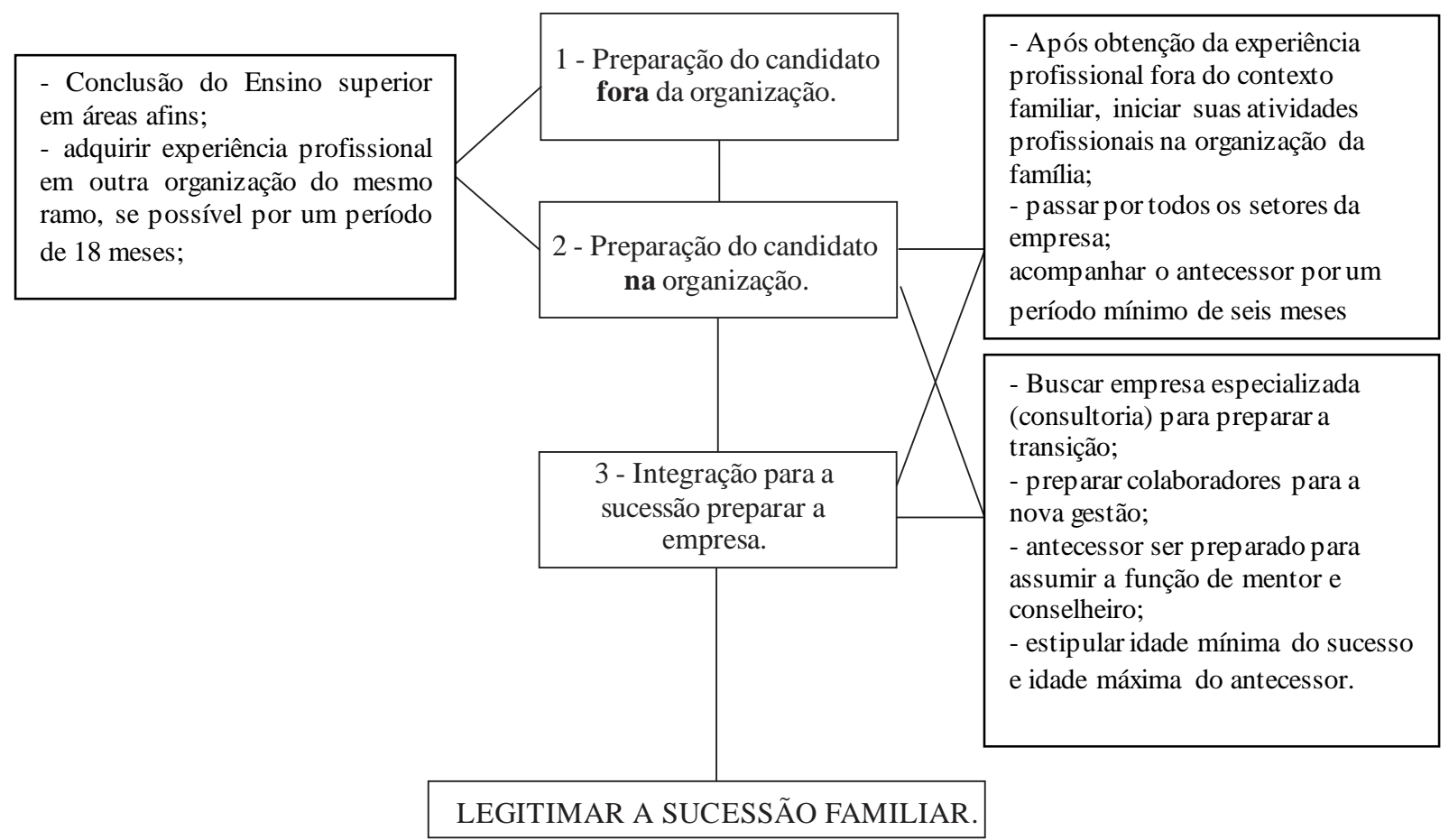

Fonte: os autores (2016)

Para Oliveira et al.(2013), a vivência em todas as áreas permite que os sucessores desenvolvam uma visão mais ampla das empresas, calcada na acumulação das experiências que acumulam ao transitarem pelos diferentes setores e funções do negócio. Segundo Vieira, Sousa Neto e Roscoe, (2010), a cultura geral, a educação formal, a constante atualização dos conhecimentos e a profunda identificação com os negócios da família fazem com que as novas gerações assimilem o espírito empreendedor e sejam propensas a inovar. 
Assim, propõem-se um planejamento com base na experiência da empresa pesquisada onde são contempladas três etapas antes de a sucessão ser legitimada: 1) preparação do candidato fora do contexto familiar, em outra empresa para buscar conhecimento e comprometimento profissional; 2) após o período de experiência adquirida fora do negócio familiar, chega o momento de aprimorar e colocar em prática outras experiências, agora com conhecimento e vivência de outros ambientes e 3) integração para a passagem do bastão/efetivar a sucessão, preparar a empresa e seus stakeholders antes mesmo de legitimar a sucessão para evitar possíveis conflitos, problemas e rejeições e acima de tudo em ter maior segurança para a continuidade do negócio familiar.

\section{CONSIDERAÇÕES FINAIS}

Este estudo buscou problematizar a condução do processo sucessório em uma empresa familiar do ramo imobiliário conduzida por mulheres. Nesse sentido, foi possível evidenciar que o processo de sucessão não foi planejado antecipadamente e que a questão de gênero não influenciou na escolha do sucessor, pois propriedade e familia são separados e legitimados na organização estudada. Contudo, foi evidenciado que o processo sucessório ocorreu por vontade própria da antecessora de se desligar dos negócios da família, mas, no entanto, constatou-se que não foi possível de início, pois a sucessora em processo não demonstrou preparo suficiente para gerir sozinha a organização.

Evidenciou-se que o processo sucessório aconteceu de forma indutiva, que as estratégias adotadas para o processo da sucessão indiretamente também foram indutivas, pois constatou-se que em nenhum momento a sucessão foi forçada e o desejo e sonhos dos filhos sempre foram respeitados. Dentre as principais estratégias adotadas destaca-se a mãe na figura de conselheira e mentora e o nível de escolaridade da sucessora, a estada dos herdeiros no exterior, para aprimorar seus conhecimentos e aprender uma nova cultura, a frequência dos filhos na organização em período de férias, a busca da herdeira por cursos técnicos voltados diretamente para o ramo.

Atestou-se que o processo sucessório foi legitimado a partir do momento da anunciação para os demais parceiros: colaboradores, clientes e fornecedores. Foi desejo da herdeira assumir os negócios da família, e manter os valores da empresa, legado deixado pelo pai. No entanto, ficaram evidentes os dificultadores da sucessão apresentados pela literatura de forma recorrente como: muita rejeição por parte dos colaboradores, gerando alta rotatividade de funcionários, restrição de alguns clientes por causa da idade da sucessora. $\mathrm{O}$ 
fato de ter 23 anos gerou receio de alguns clientes de início, mas que no decorrer das entrevistas verificou-se que essa suposta rejeição por parte de alguns clientes foi sanada. Com relação ao relacionamento mãe e filha, constataram-se alguns momentos de invasão de espaço, falta de comunicação, gerando discordâncias e conflitos, pois de acordo com a antecessora o processo da sucessão foi antecipado involuntariamente por parte da herdeira.

Em relação ao fator dilemas e controvérsias familiares, foi possível verificar que propriedade e familia sempre foram separados na organização estudada, porém, o quesito gestão e familia nos primórdios do processo sucessório da imobiliária não eram separados, uma vez que assuntos pertinentes a negócios não tinham horário e local para serem abordados. Ao despertarem para esse problema, tanto a antecessora como a sucessora, criaram regras e a situação foi amenizada com a saída da filha da casa da mãe.

Por fim, identificamos algumas alternativas para o aperfeiçoamento do processo sucessório da organização estudada. Alguns deles apresentados pelas próprias entrevistadas, que servem como exemplo e apoio para outras empresas com características semelhantes e que estão pensando em conduzir o seu processo sucessório. Também é apresentado um esquema adaptado de acordo com o contexto deste estudo de caso, esquematizando as etapas que o processo sucessório poderia ter percorrido para poder evitar possíveis conflitos, rejeições e ser eficaz na sua condução.

Portanto, a principal contribuição do estudo para o avanço do conhecimento consiste em evidenciar que determinação, desejo de prosperar e persistência são elementos-chaves para o sucesso de um empreendimento. O processo sucessório planejado é relevante e estratégico para as empresas, mas não é o único elemento que corrobora para que a organização tenha sucesso. A descrição da trajetória, particularidade e sistemática de condução da sucessão de mãe para filha elenca uma característica das pequenas e médias empresas familiares brasileiras, que dificilmente contratam profissionais qualificados para organizar e planejar o processo sucessório. O processo ocorre de maneira não planejada e informal e muitas vezes é decisivo para o fracasso/falência da empresa. Portanto, as especificidades descritas são relevantes para elucidar um case de sucesso e podem trazer insights para outros gestores se apropriarem de condutas que levarão ao sucesso do processo sucessório na sua organização.

Os fatores limitadores deste estudo estão relacionados ao fator metodológico, uma vez que não foi possível entrevistar o outro herdeiro, o filho societário e antigos funcionários que compuseram a sucessão no seu início; e ao fator teórico, pois de acordo com a própria 
literatura apresentada na justificativa deste estudo, o assunto sucessão gerido por mulheres ainda é recente, e, portanto, há poucos estudos reportando a essa temática específica.

Para sugestões de novas pesquisas, este trabalho aponta necessidades em compreender melhor os seguintes aspectos: quais são os principais focos de conflitos vivenciados no decorrer dos processos de sucessão; identificar as principais dificuldades encontradas pelo antecessor em transferir seu posto, bem como as dificuldades do sucessor em assumir a sucessão; realizar multicasos comparando as discrepâncias e similaridades do processo sucessório de pequenas e médias empresas; analisar processos sucessórios passado de pai para filha e comparando semelhanças e diferenças com o caso estudado. Enfim, espera-se que a presente pesquisa contribua com os processos sucessórios conduzidos por mulheres em pequenas empresas familiares e que novas pesquisas possam ser ampliadas e motivadas a partir desta. Para futuras pesquisas, recomenda-se fazer estudo similar em empresas de grande porte geridas por mulheres, para verificar como são efetuados os encaminhamentos nesse tipo de organização para garantir a perenidade do empreendimento.

\section{REFERÊNCIAS}

Ahrens, J. P.; Landmann, A. \& Woywode, M. (2015).Gender preferences in the CEO successions of family firms: Family characteristics and human capital of the successor. Journal of Family Business Strategy, 6(2), 86-103.

Bardin, L.(1977). Análise de conteúdo. Lisboa: Edições, 70. (2004). Análise de conteúdo (3a ed.). Lisboa: Edições, 70.

Bird, B.; Welsch, H.; Astrachan, J. H. \& Pistrui, D. (2002).Family business research: The evolution of an academic field. Family Business Review, 15(4), 337-350.

Blumentritt, T.; Mathews, T. \& Marchisio, G. (2013). Game theory and family business succession an introduction. Family Business Review, 26(1), 51-67.

Borges, A. F.; Lima, J. \& Carvalho, F. (2008). Interação entre indivíduos, família e empresa na construção do processo de sucessão em uma empresa familiar. XXXII EnANPAD, Rio de Janeiro, Brasil, 32. 
Bornholdt, W. (2005). Governança na empresa familiar: implementação e prática. São Paulo: Bookman.

Cappuyns, K. (2007). Women behind the scenes in family businesses. Electronic Journal of Family Business, vol.1, n 1, pp. 38-61.

Cruz Machado, R. M.; Wetzel, U. \& Rodrigues, M. E. (2008). A experiência de sucessão para herdeiras de empresas familiares do Rio de Janeiro. Cadernos Ebape.br, (3), 1-24.

Dahl, G. B. \& Moretti, E. (2008). The demand for sons. The Review of Economic Studies, 75.4: $1085-1120$.

Debicki, B. J.; Matherne, C. F.; Kellermanns, F. W.\& Chrisman, J. J. (2009). Family business research in the new millennium an overview of the who, the where, the what, and the why. Family Business Review, 22(2), 151-166.

Departamento Intersindical de Estatística e Estudos Socioeconômicos (2016). Recuperado de https://www.dieese.org.br/analiseped/2016/2015pedmulherbsb.pdf. Acesso em 5 de out. 2017.

Dugan, A. M.; Krone, S. P.; LeCouvie, K.; Pendergast, J. M.; Kenyon-Rouvinez, D. H. \& Schuman, A. M. (2011). A woman's place: The crucial roles of women in family business. Unite States: Macmillan.

Dumas, C. (1998). Women's pathways to participation and leadership in the family-owned firm. Family Business Review, 11(3), 219-228.

Family Business Network (FBN) (2016). Disponível em < http://www.fbn-br.org.br/>. Acessado em 11 out. 2017.

Ferreira, M. A. D. A. (2015). Processo sucessório em organizações brasileiras: um estudo com uso de ground theory. Dissertação de doutorado, Universidade de São Paulo, São Paulo, SP, Brasil.

Fitzgerald, M. A.; Winter, M.; Miller, N. J. \& Paul, J. (2001). Adjustment strategies in the family business: Implications of gender and management role. Journal of family and Economic issues, 22(3), 265-291. 
Gersick, K. E.; Davis, J. A.; Hampton, M. M. \& Lansberg, I. (1997).De geração para geração: ciclos de vida das empresas familiares. São Paulo: Negócio.

Grzybovski, D.; Hoffmann, P. Z. \& Muhl, E. E. (2008). Estratégia e sucessão na gestão de empresas familiares: um estudo do caso Gerdau. $V$ Encontro de Estudos Organizacionais.

Gupta, V. \& Levenburg, N. M. (2013). 16 Women in family business: three generations of research. Handbook of Research on Family Business, 346.

Haberman, H. \& Danes, S. M. (2007). Father-daughter and Father-son family business management transfer comparison: Family FIRO model application. Family Business Review, 20(2), 163-184.

Instituto Brasileiro de Geografia e Estatística- IBGE (2014). Empresa familiar. Recuperado de

http://www.ibge.gov.br/home/estatistica/economia/comercioeservico/pas/analisepas 99 .shtm. Acesso em 5 de out. 2017.

Janjuha-Jivraj, S. \& Woods, A. (2002). Successional issues within Asian family firms learning from the Kenyan experience. International Small Business Journal,20(1), $77-94$.

Jimenez, R. M. (2009). Research on women in family firms current status and future directions. Family Business Review, 22(1), 53-64.

Kets de Vries, M.; Carlock, R. S. \& Florent-Treacy, E. (2009). A empresa familiar no divã: uma perspectiva psicológica. Porto Alegre: Bookman.

Leach, P. \& Bogod, T. (2006). Claves de la empresa familiar. Madrid: Instituto de Estudios Económicos.

Lambrecht J. (2005). Multigenerational transition in family business: a new explanatory model. Family Business Review, 18(4), 267-82.

Leone, N. M. D. C. P. (2004). O processo sucessório em empresas familiares: o exemplo dos comerciantes e o processo no Saara. Organizações \& Sociedade, 11(29), 149-172. 
Lerner, M. \& Malach-Pines, A. (2011). Gender and culture in family business: A ten-nation study. International Journal of Cross Cultural Management, 11(2), 113-131.

Machado, H. V.; Silveira, A.; Hoeltgebaum, M., \& Gouveia, A. (2008, setembro). Significados de sucesso e fracasso nos negócios: o que dizem mulheres empreendedoras. XXXII Encontro Nacional da Associação dos Programas de Pósgraduação em Administração, Rio de Janeiro, RJ, Brasil, 32.

Massis, A.; Chua, J. H. \& Chrisman, J. J. (2008).Factors preventing intra-family succession. Family Business Review, 21(2), 183-199.

Michael-Tsabari, N. \& Weiss, D. (2015).Communication traps: applying game theory to succession in family firms. Family Business Review, 28(1), 26-40.

Oliveira, D. D. P. R. (2006). Empresa familiar: como fortalecer o empreendimento e otimizar o processo sucessório. São Paulo: Editora Atlas SA.

Oliveira, L. G. M., \& da Silva, G. A. V. (2012). Sucessão em uma empresa familiar: valores, racionalidades e dilemas. Revista de Administração Faces Journal, 11(2).

Oliveira, J. L.; Albuquerque, A. L. \& Pereira, R. D. (2013). De "filho do dono" a dirigente ilustre: caminhos e descaminhos no processo de construção da legitimidade de sucessores em organizações familiares. Revista de Administração, 48(1), 21-33.

Oliveira Pecanha, A. R., \& Barbara de Oliveira, S. (2015). Empresa familiar, sim! Mas qual o problema, se a gestão é profissional? Navus-Revista de Gestão e Tecnologia, 5(3).

Passos, É.; Bernhoeft, R.;\& Teixeira, W. (2006). Família, família, negócios à parte: como fortalecer laços e desatar nós na empresa familiar. São Paulo: Gente.

Petry, L. I. \& Nascimento, A. M. (2009). Um estudo sobre o modelo de gestão e o processo sucessório em empresas familiares. Revista Contabilidade \& Finanças, 20(49), 109125.

Santos, A. P. dos, Oliveira, C. D. C. de \& Sehnem (2016, agosto)S. Sucessão familiar: fragilidades do campo e direções futuras de pesquisa. $5^{\circ}$ Fórum Internacional Ecoinovar $1^{a}$ Conferência Internacional de Sustentabilidade e Inovação Santa Maria/RS - 9 a 12 de agosto de 2016. 
Salvato, C. \& Corbetta, G. (2013). Transitional leadership of advisors as a facilitator of successors' leadership construction. Family Business Review, 26(3), 235-255.

Scheffer, A. B. B. (1995). Fatores dificultantes e facilitadores ao processo de sucessão familiar. Revista de Administração da Universidade de São Paulo, 30(3).

Schlepphorst, S. \& Moog, P. (2014). Left in the dark: Family successors' requirement profiles in the family business succession process. Journal of Family Business Strategy, 5(4), 358-371.

Schröder, E.; Schmitt-Rodermund, E. \& Arnaud, N. (2011).Career choice intentions of adolescents with a family business background. Family Business Review, 24(4), 305321.

Serviço Brasileiro de Apoio às Micro e Pequenas empresas. Empresa familiar, desafios da sucessão familiar. Disponível em $<$ http://www.sebrae.com.br/empresafamiliar/sucessaofamiliar>. Acesso em 5 de out. 2017.

Sharma, P.; Chrisman, J. J.; Pablo, A. L. \& Chua, J. H. (2001).Determinants of initial satisfaction with the succession process in family firms: A conceptual model. Entrepreneurship Theory and Practice, 25(3), 17-36.

Vera, C. F. \& Dean, M. A. (2005). An examination of the challenges daughters face in family business succession. Family Business Review, 18(4), 321-345.

Vieira, A.; Sousa Neto, J. A. \& Roscoe, M. (2010). Relações de influência entre dimensões da transgeracionalidade e dimensões da cultura: estudo de casos de empresas familiares. VI Encontro da Divisão de Estudos Organizacionais-EnEO. Anais... Florianópolis, 6.

Yin, R. K. \& Pinnelli, S. (2005). Lo studio di caso nella ricerca scientifica: progetto e metodi. Roma: Armando Editore. 